\title{
Relationship of anxiety with emotional and behavioral problem in Madrasah Tsanawiyah Hidayatullah islamic boarding school students, Denpasar
}

\author{
Rabiatul Udawiyah, \\ Cokorda Bagus Jaya Lesmana, \\ Lely Setyawati
}

Department of Psychiatry, Faculty of Medicine Udayana University/Sanglah General Hospital Bali, Indonesia

Cite this article:

Udawiyah R, Lesmana CBJ, Setyawati L.Relationship of anxiety with emotional and behavioral problem in Madrasah Tsanawiyah Hidayatullah Islamic boarding school students, Denpasar. Journal of Clinical and Cultural Psychiatry. 2020; I (I): I-3.

\section{Corresponding author:}

Cokorda Bagus Jaya Lesmana Department of Psychiatry, Faculty of Medicine Udayana University / Sanglah General Hospital Jl. Kesehatan No I, Bali 80I I4, Indonesia cokordabagus@unud.ac.id

\begin{abstract}
Background: Emotional and behavioral problem are persistent and recurring problem that observed in teenagers specifically students. Anxiety is the most common mental health problem found in Islamic boarding school students. This research aims to find out the relationship of anxiety with emotional and behavioral problem in Madrasah Tsanawiyah, Hidayatullah Islamic Boarding School Students, Denpasar.

Patients and Methods: The study was an analytical cross-sectional study with 89 students met inclusion and exclusion criteria. This research used the Strength and Difficulties Questionnaire (SDQ) to measure emotional and behavioral problems and Beck Anxiety Inventory (BAI) to measure the student's anxiety level. The correlation was analyzed by using Spearman's correlation test.

Results: Forty-five (50.8\%) students experience abnormal emotional and behavioral problems with $30(30 \%)$ the students mostly had moderate level anxiety. The correlation between the anxiety with emotional and behavioral problems had an $\mathrm{R}$ value of $0.366(\mathrm{p}<0.001)$.

Conclusion: There was a moderate positive relationship between anxiety with emotional and behavioral problems in Madrasah Tsanawiyah Islamic boarding school Hidayatullah students.
\end{abstract}

Keywords: anxiety, emotional and behavioral problems, $M T S, S D Q, B A I$

\section{Introduction}

Students who study in boarding schools usually experience anxiety due to separation from parents, change of residence and increased in study, especially religious studies. ${ }^{1}$ Anxiety, including separation anxiety, is the most common mental disorder. Based on population studies, there were $7.7 \%$ cases of anxiety in students aged $13-17$ years and $6.6 \%$ cases at ages $18-64$ years. $^{2}$

A meta-analysis study showed that the general prevalence of student anxiety in China was $0.9 \%$, Afghanistan 28.3\%, Italy 2.4\%, and Mexico 29.8\%, while the global prevalence in 2013 was $7.3 \%$, i.e. 1 of 14 people worldwide can experience anxiety problems and 1 person out of 9 will experience anxiety problems annually. ${ }^{3}$ The prevalence of anxiety related problems in Indonesia showed that $10 \%$ of the population aged 15 years and over in 14 million people in Indonesia experience emotional mental disorders that manifest as anxiety and depression problems. ${ }^{4,5}$

Anxiety can occur in various segments of the population, including students, especially students who study at the boarding school. This anxiety is associated with the amount of stressors that are obtained by students who attend the boarding system such as feeling homesick, academic pressure, lack of parental support and other things. ${ }^{6}$ A research found that students' anxiety in boarding schools is greater than the anxiety of students at regular school (39.3\% vs $20.2 \%){ }^{7}$ 
Students with anxiety problems tend to have problematic behaviors such as hyperkinetics, emotional instability and attention seeking. ${ }^{8}$ Aggressive behavior is also often observed, because when a condition occurs where students are unable to handle it and causing him to feel uncomfortable, he will activate the "fight or flight" response so that they can behave in an abusive and aggressive manner. Students with anxiety problems can be characterized by a number of behaviors, such as trouble sleeping in a separate room with their parents, avoiding various activities for no apparent reason, as well as having a high temperament to those around them. ${ }^{9}$ Academic burden especially memorizing the verses of the Qur'an and difficult general subjects such as Mathematics and Science. This lesson has a significant correlation with the occurrence of anxiety problems in students. ${ }^{10}$

The high anxiety problems that occur in students with a boarding education system and the influence of anxiety on emotional and behavioral problems causes researchers to feel interested in researching this. The absence of reports regarding the relationship between anxiety and Islamic boarding school in Bali also encourages researchers to conduct this research. This study was conducted to determine the relationship between anxiety and emotions and behavior in students in Islamic boarding schools.

\section{Patients and Methods}

This study is a cross sectional study that aims to determine the relationship between anxiety problems with emotional and behavioral problems in Islamic boarding school students. The research was conducted at the Madrasah Tsanawiyah (MTS) Hidayatullah Islamic Boarding School in Denpasar in May 2019. Written informed consents were obtained from the legal guardians of the respective subjects.

The subjects were all MTTS students who lived in the Hidayatullah Islamic Boarding School in Denpasar. The inclusion criteria of this study are: (1) all students who live in Islamic boarding schools, (2) 12-15 years old, (3) understand Indonesian; while the exclusion criteria: (1) students who do not live in boarding schools, (2) have physical and mental illness.

Anxiety measured using the Beck Anxiety Inventory (BAI) with 21 items that measure physical, cognitive, and emotional aspects. Subjects will choose what they felt during the past four weeks and then put in a score that has a range from 0 to 3 . The total score will indicate the subject's anxiety level. BAI has a maximum score of 63 with the following ratings: 0-7: minimum level of anxiety, 8-15: mild anxiety, 16-25: moderate anxiety, 26-63: severe anxiety.

Measurement of emotional and behavioral problem is done using Strength and Difficulties Questionnaire (SDQ). SDQ assessment has 25 psychological aspects assessment points which are divided into five subscales: emotional symptom, conduct problem, hyperactivity-inattention, peer problem, and prosocial. ${ }^{11}$

Characteristics of the sample are presented descriptively, using tables. Hypothesis testing using the Spearman test or Pearson test de- pends on the distribution of data distribution. If the data distribution is normal Pearson correlation test will be used, whereas if the data distribution is not normal Spearman correlation test will be used. ${ }^{12} \mathrm{~A}$ $\mathrm{p}$-value of $<.0 .05$ is considered statistically significant.

\section{Results}

There were 50 male students and 39 female students enrolled in this study. The average age of study subjects was $13 \pm 0.7$ years. Table 1 shows a detailed subjects' characteristics, while Table 2 showed that there were no differences in anxiety disorders and emotional/ behavioral problems between male and female.

Table 1. Research Subject Characteristics

\begin{tabular}{|c|c|}
\hline Characteristic & Value \\
\hline Age, years (mean $\pm \mathrm{SD})$ & $13 \pm 0.707$ \\
\hline \multicolumn{2}{|l|}{ Sex, $n(\%)$} \\
\hline Male & $50(56.2 \%)$ \\
\hline Female & $39(43.8 \%)$ \\
\hline \multicolumn{2}{|l|}{ Number of siblings, $\mathbf{n}(\%)$} \\
\hline 1 & $12(14.5 \%)$ \\
\hline 2 & $37(41.6 \%)$ \\
\hline 3 & $25(28.1 \%)$ \\
\hline 4 & $10(11.2 \%)$ \\
\hline 5 & $3(3.4 \%)$ \\
\hline 6 & $2(2.2 \%)$ \\
\hline \multicolumn{2}{|c|}{ Reason to reside in Islamic boarding school, $\mathrm{n}(\%)$} \\
\hline Studying religion & $13(14.6 \%)$ \\
\hline Forced & $7(7.9 \%)$ \\
\hline Want to be independent & $15(16.9 \%)$ \\
\hline Want to be a hafidz & $4(4.5 \%)$ \\
\hline Searching for knowledge & $9(10.1 \%)$ \\
\hline Studying & $17(19.1 \%)$ \\
\hline Others & $65(26.9 \%)$ \\
\hline \multicolumn{2}{|l|}{ Reason to board at the school, $n(\%)$} \\
\hline Own desire & $56(62.9 \%)$ \\
\hline Parents' wish & $33(37.1 \%)$ \\
\hline \multicolumn{2}{|c|}{ Who financed the stay at boarding school, $n(\%)$} \\
\hline Parents & $87(97.8 \%)$ \\
\hline Other relative & $2(2.2 \%)$ \\
\hline \multicolumn{2}{|l|}{ Parent's nature, n(\%) } \\
\hline Kind & $58(65.2 \%)$ \\
\hline Proud & $6(6.7 \%)$ \\
\hline So-so & $10(11.2 \%)$ \\
\hline Normal & $1(1.1 \%)$ \\
\hline Grumpy and kind & $2(2.2 \%)$ \\
\hline Loving & $4(4.5 \%)$ \\
\hline Caring & $8(9.0)$ \\
\hline \multicolumn{2}{|c|}{ Been punished at the boarding school } \\
\hline Yes & $89(100 \%)$ \\
\hline No & $0(0 \%)$ \\
\hline
\end{tabular}

Table 2. BAI and SDQ distribution of the study subjects

\begin{tabular}{llll}
\hline & Male & Female & p-value \\
\hline BAI & & & 0.837 \\
Minimum & $6(12)$ & $6(15.4)$ & \\
Mild & $15(30)$ & $10(25.6)$ & \\
Moderate & $18(36)$ & $12(30.8)$ & \\
Severe & $11(22)$ & $11(28.2)$ & \\
\hline SDQ & & & 0.954 \\
Normal & $12(24)$ & $10(25.6)$ & \\
Borderline & $12(24)$ & $10(25.6($ & \\
Abnormal & $26(52)$ & $19(48.7)$ & \\
BAI: Beck Anxiety Disorder; SDQ: strength and difficulties disorder &
\end{tabular}

Table 3. Correlation between anxiety level (BAI) and emotional/behavioral problems $(S D Q)$

\begin{tabular}{lll}
\hline Variables & Emotional and behavioral problem (SDQ) \\
\hline Anxiety & $\mathrm{R}$ & 0.366 \\
(BAI) & $\mathrm{p}$-value & $<0.001$ \\
& $\mathrm{~N}$ & 89 \\
\hline BAI: Beck Anxiety Disorder; SDQ: strength and difficulties disorder;
\end{tabular}

$\mathrm{R}$ : Spearman's correlation coefficient

The Spearman's correlation test was used to see the correlation between BAI and SDQ. The test result said that BAI showed moderately positive correlation to SDQ $(\mathrm{R}=0.366, \mathrm{p}<0.001)$. The scatter plot between the two variables is shown in Figure1. 


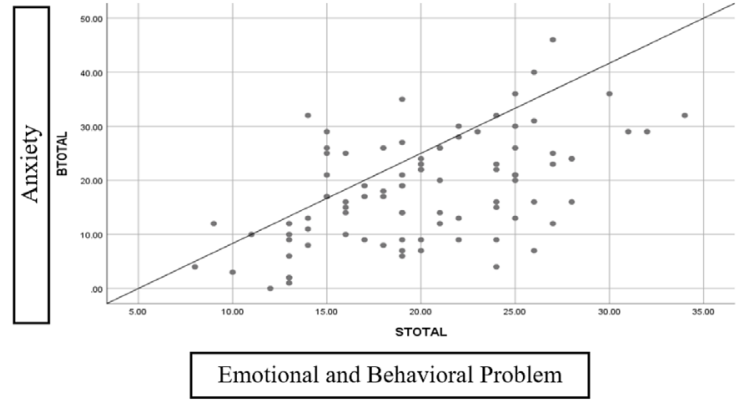

Fig 1. Score Linearity of total BAI dan $S D Q$

\section{Discussion}

Adolescence is often associated with deviation of emotional and behavioral problems as a result of pressures experienced due to changes that occur in him. ${ }^{11,12}$ Changes that occur in adolescents are associated with sexual hormones that are developing. In this phase, biological, psychological and social changes also observed. ${ }^{13}$

In this study, anxiety among students based on sex revealed that men and women are both alike, experienced an increased risk of anxiety. A study found that there were fewer male students than female students. ${ }^{7}$ The prevalence of anxiety in this study was moderate with the results of 30 students (30\%) experience moderate anxiety but did not explain what caused the student's anxiety.

The characteristics of anxiety, including almost every event are felt as things that worrying causing fear and anxiety; a strong and unstable emotions, frequent anger, and often in a state of rage or an uproar; and always followed by various kinds of fantasy, delusion, illusion, and delusion of persecution. ${ }^{14}$ This can cause emotional and behavioral problems for students in Islamic boarding schools.

There are several factors that cause anxiety. Based on the theory of psychoanalysis, anxiety is an emotional conflict between the id, the ego and the superego, this is related in line with these changes, adolescents are also confronted with development tasks that must be fulfilled, if he/she unable to overcome, it could cause some form of anxiety. ${ }^{15}$ This anxiety will have an impact on emotional and behavioral problems. It is said that anxiety problems relationship with emotional and behavioral problems is more benign, and has a positive relationship with externalization disorder.

Although it seems inconsistent, this is due to an overlap between aspects of anxiety: behavioral hindrance and social withdrawal. Behavioral hindrance are defined as a tendency to show fear, restrain anger, keep quiet and withdraw from the existence of new stimuli, especially in people with social anxiety problems. This inhibition of behavior is a protective factor against aggressive behavior in students, but increase the risk of emotional problems and social behavior and depression. Analysis shows that there is significant relationship between anxiety with emotional and behavioral problem in Madrasah Tsanawiyah Islamic Boarding School students.

The positive relationship between anxiety and emotional and behavioral problems means the higher the level of anxiety, the higher the emotional and behavioral problems in Madrasah Tsanawiyah Is- lamic Boarding School students. The positive relationship between anxiety and emotional and behavioral problems means the higher the level of anxiety, the higher the emotional and behavioral problems that arise.

The positive relationship between anxiety and emotional problems, behavioral problems, hyperactivity problems and peer problems is supported by several previous studies ${ }^{6-8}$ A study shows that there is a significant relationship between the presence of anxiety in students can cause emotional and behavioral problem that are statistically significant $(p=0.019) .{ }^{6}$ This anxiety is associated with a lot of stressors that are obtained by students who attend school with the dormitory system such as feeling homesick, academic pressure, lack of parent support and other things. It was found that students with anxiety problems tend to have problem behaviors such as hyperkinetics, unstable emotions and attention seeking. ${ }^{16}$

\section{Conclusion}

There is a moderate positive relationship between anxiety and emotional and behavioral problems in MTS Hidayatullah students.

\section{Acknowledgement}

The authors report no conflict of interests.

\section{Reference}

1. Wang JN, Liu L, Wang L. Prevalence and associated factors of emotional and behavioural problems in Chinese school adolescents: a cross-sectional survey. Child Care Health Dev. 2014;40(3):319-26. doi: 10.1111/cch.12101

2. Bandelow B, Michaelis S. Epidemiology of anxiety disorders in the 21st century. Dialogues Clin Neurosci. 2015;17(3):32735. Available at: https://www.ncbi.nlm.nih.gov/pmc/articles/ PMC4610617/

3. Baxter AJ, Scott KM, Vos T, Whiteford HA. Global prevalence of anxiety disorders: a systematic review and meta-regression. Psychol Med. 2013;43(5):897-910. doi:10.1017/ S003329171200147X

4. Hartini N, Fardana NA, Ariana AD, Wardana ND. Stigma toward people with mental health problems in Indonesia. Psychol Res Behav Manag. 2018;11:535-41. doi:10.2147/PRBM. S175251

5. Sari SP, Yuliastuti E. Investigation of attitudes toward mental illness among nursing students in Indonesia. Int J Nurs Sci. 2018;5(4):414-8. doi:10.1016/j.ijnss.2018.09.005

6. Wahab S, Rahman FN, Wan Hasan WM, et al. Stressors in secondary boarding school students: association with stress, anxiety and depressive symptoms. Asia Pac Psychiatry. 2013;5(Suppl 1):82-9. doi:10.1111/appy.12067

7. Evans-Campbell T, Walters KL, Pearson CR, Campbell CD. Indian boarding school experience, substance use, and mental health among urban two-spirit American Indian/Alaska natives. Am J Drug Alcohol Abuse. 2012;38(5):421-7. doi:10.3109/009 
8. wadare Y, Kamei Y, Usami M, et al. Behavioral symptoms a in children with anxiety disorder. Pediatr Int. 2015;57(4):690-3. doi: $10.1111 /$ ped.12620

9. Moswela B. Boarding schools as perpetrators of students' behaviour problems. J Soc Sci. 2006;13(1):37-41. Available at: http://krepublishers.com/02-Journals/JSS/JSS-13-0-000000-2006-Web/JSS-13-1-001-082-2006-Abst-Text/JSS-13-1037-041-2006-377-Moswela-B/JSS-13-1-037-041-2006-377Moswela-B-Text.pdf

10. Manninen M, Pankakoski M, Gissler M, Suvisaari J. Adolescents in a residential school for behavior disorders have an elevated mortality risk in young adulthood. Child Adolesc Psychiatry Ment Health. 2015;9:46. doi:10.1186/s13034-015-0078-Z

11. Engqvist U, Rydelius PA. Death and suicide among former child and adolescent psychiatric patients. BMC Psychiatry. 2006;6:51. doi:10.1186/1471-244X-6-51

12. Karimy M, Fakhri A, Vali E, et al. Disruptive behavior scale for adolescents (DISBA): development and psychometric properties. Child Adolesc Psychiatry Ment Health. 2018;12:17. doi:10.1186/s13034-018-0221-8
13. Saputra F, Yunibhand J, Sukratul S. Relationship between personal, maternal, and familial factors with mental health problems in school-aged children in Aceh province, Indonesia. Asian J Psychiatr. 2017;25:207-12. doi: 10.1016/j.ajp.2016.10.025

14. Brooks H, Irmansyah I, Lovell K, et al. Improving mental health literacy among young people aged 11-15 years in Java, Indonesia: co-development and feasibility testing of a culturally-appropriate, user-centred resource (IMPeTUs) - a study protocol. BMC Health Serv Res. 2019;19(1):484. doi:10.1186/s12913019-4328-2

15. Arjadi R, Patel V. Q\&A: Scaling up delivery of mental health treatments in low and middle income countries: interviews with Retha Arjadi and Vikram Patel. BMC Med. 2018;16(1):211. doi:10.1186/s12916-018-1209-1

16. Brooks H, James K, Irmansyah I, et al. Exploring the potential of civic engagement to strengthen mental health systems in Indonesia (IGNITE): a study protocol. Int J Ment Health Syst. 2018;12:49. doi:10.1186/s13033-018-0227-x 